\title{
SAMPLING FOR COMPLETENESS: AN EXAMPLE FROM THE YORKTOWN FORMATION (PLIOCENE) OF VIRGINIA
}

DALEY, G.M., Department of Geological Sciences, Virginia Polytechnic Institute and State University, Blacksburg, Virginia, 24061-0420, U.S.A.

Individual species are unevenly distributed throughout even the most homogeneous deposit due to paleoenvironmental and geographic variation, as well as simple chance. It has been suggested by some workers that very diverse fossil deposits, such as some of those from the Gulf and Atlantic Coastal Plains of North America, can not be adequately sampled for paleocommunity studies without taking enormous collections. However, because of patchiness in the occurrence of paleocommunities and variation in single paleoenvironmental settings, entire formations can never be sampled adequately by digging one hole at one horizon at one locality. However, with a more involved sampling scheme it is possible to adequately analyze the diversity patterns within and between paleocommunities .

As an example, samples were taken at closely spaced stratigraphic levels from several members of the Yorktown Formation at several localities in Virginia. The fossil mollusks in each sample were identified to the species level, and the diversities tabulated. Statistically coherent groups of samples were identified using factor analysis. Each group contained samples from the same stratigraphic interval, and represents one paleoenvironment or sub-environment. For the Yorktown Formation, a combination of the three most diverse samples within each group was usually sufficient to characterize the diversity of lower diversity groups (15-30 species), while four samples were required for higher diversity groups (50-60 species). Additional samples yielded only a few new rare species $(<5 \%)$ or none at all.

With the addition of samples from more sub-environments from either different localities or different stratigraphic intervals at the same locality, a large percentage of the total number of species described from the Yorktown Formation can be collected.

Each sub-environment at each locality yields a limited number of species, regardless of how many samples are taken, or how large the samples are. In order to collect a large percentage of the several hundred species described from the Yorktown formation, bulk samples of the total suite of contained sub-environments need to be taken at several different geographic locations.

The same should be true for other stratigraphic units. Complete characterization of the fauna from a single paleoenvironment or sub-environment is possible with limited geographic sampling. Characterization of an entire stratigraphic unit requires that all contained sub-environments be sampled, but not that enormous individual samples need to be taken. The total aggregate sample size needed to characterize a particular local sub-environment will vary with the total contained diversity, but by replicate sampling it is possible to characterize the diversity. 